\title{
Dynamic Behavior of Reverse Flow Reactor for Lean Methane Combustion
}

\author{
Yogi W. Budhi, M. Effendy, Yazid Bindar \& Subagjo \\ Department of Chemical Engineering, Institut Teknologi Bandung \\ J1. Ganesha 10, Bandung 40132, Indonesia \\ Email: Y.Wibisono@che.itb.ac.id
}

\begin{abstract}
The stability of reactor operation for catalytic oxidation of lean $\mathrm{CH}_{4}$ has been investigated through modeling and simulation, particularly the influence of switching time and heat extraction on reverse flow reactor (RFR) performance. A mathematical model of the RFR was developed, based on onedimensional pseudo-homogeneous model for mass and heat balances, incorporating heat loss through the reactor wall. The configuration of the RFR consisted of inert-catalyst-inert, with or without heat extraction that makes it possible to store the energy released by the exothermic reaction of $\mathrm{CH}_{4}$ oxidation. The objective of this study was to investigate the dynamic behavior of the RFR for lean methane oxidation and to find the optimum condition by exploring a stability analysis of the simple reactor. The optimum criteria were defined in terms of $\mathrm{CH}_{4}$ conversion, $\mathrm{CH}_{4}$ slip, and heat accumulation in the RFR. At a switching time of $100 \mathrm{~s}$, the $\mathrm{CH}_{4}$ conversion reached the maximum value, while the $\mathrm{CH}_{4}$ slip attained its minimum value. The RFR could operate autothermally with positive heat accumulation, i.e. $0.02 \mathrm{~J} / \mathrm{s}$. The stability of the RFR in terms of heat accumulation was achieved at a switching time of $100 \mathrm{~s}$.
\end{abstract}

Keywords: fixed bed reactor; oxidation; modeling and simulation; dynamic behavior.

\section{Introduction}

The major energy source used nowadays is fossil fuel, which gives rise to a profound negative impact on human health and the environment. Lean methane emission vented from fossil fuel industries such as coalmines and oil/gas companies, even at low concentrations, has been recognized as extremely dangerous. It has been reported by Hayes [1] that methane has a global warming potential that is 21 times higher than that of $\mathrm{CO}_{2}$. If those methane emissions can be captured in some way, they could potentially be used to generate thermal energy due to methane's exothermic reaction. Capturing methane emissions means two things: global warming potential reduction up to $87 \%$ and potential thermal energy generation. Oxidation of lean methane concentrations smaller than $1 \%-\mathrm{v}$ can be conducted over appropriate catalysts, such as Pt or Pd active site [2].

Received June $5^{\text {th }}, 2013$, Revised February $19^{\text {th }}, 2014$, Accepted for publication June $25^{\text {th }}, 2014$.

Copyright (C) 2014 Published by ITB Journal Publisher, ISSN: 2337-5779, DOI: 10.5614/j.eng.technol.sci.2014.46.3.5 
A large amount of methane may be continuously discharged in the atmosphere from coalmine ventilation air and compressor houses for pipeline systems for natural gas distribution. A single compressor shaft can emit over $500,000 \mathrm{~m}^{3}$ (STP)/h of ventilation air in which the methane content could be up to $1 \%$-v [3]. The abatement of such emissions therefore becomes indispensable from an environmental and economic viewpoint as the gaseous fuel is inadvertently lost, which contributes to the greenhouse gas effect. Until recently, no technology has been offered for satisfactorily treating the lean methane below 1\%-v [4]. In addition, the emission of methane has typical characteristics such as ambient temperature and dynamic concentration. Treatment of low-temperature lean methane emission using a catalytic fixed bed reactor with one-through operation usually requires a preheater to achieve the reaction temperature due to its low adiabatic temperature rise. As a consequence, its dynamic concentration may induce reactor instability to some extent. Therefore, a proper operation method for reduction of methane emission is highly required.

The development of a reverse flow reactor (hereinafter referred to as RFR) was already commenced a few decades ago for lean oxidation. It began with reactor operation for trapping the heat released by the exothermic reaction inside the materials that have a high heat capacity, usually placed at the outer part of the catalytic section. The concept of the RFR was originally proposed by Cottrell [5] for pollutant removal. Subsequent applications of this reactor were motivated by the successful development of $\mathrm{SO}_{2}$ oxidation by Boreskov, et al. [6] and Boreskov \& Matros [7]. It was reported that a higher conversion could be achieved by using an RFR. The study of reverse flow operation (hereinafter referred to as RFO) through modeling and simulation spans from a very simple first-order kinetic reaction to full elementary reaction steps, and from onedimensional pseudo-homogeneous models [8] to two-phase model accounting for gas-solid temperature difference, ignoring effective axial dispersion [9] or including effective axial dispersion [10,11], or including mass transfer limitations inside and outside the catalyst particles [12-14]. At a higher complexity level, Sapundzhiev, et al. [15] developed a two-dimensional heterogeneous model including radial diffusion and heat and mass transfers between phases. Other applications of reverse flow operation concerned oxylene oxidation to phthalic anhydride as a way to decrease the hot spot temperature [16], $\mathrm{NO}_{\mathrm{x}}$ reduction [17-19], and methanol synthesis $[9,12,14,20]$, $\mathrm{NH}_{3}$ oxidation with full elementary reaction steps using periodic lower feed concentration and side feeding of the RFR [21,22]. Matros and Bunimovich [4] comprehensively reviewed the theory and application of the RFR.

For the purpose of regenerative heat exchange, the use of an RFR for exothermic reactions has been proven. When compared to a packed bed reactor with utilization of hot reactor effluent for preheating the feed gas, an RFR may 
indicate higher energy efficiency due to direct contact between gas and solid material for storing energy [23]. As mentioned before, the energy released by the exothermic reaction can be saved inside the down part of the inert material, so that when changing the flow direction, the cold feed gas from the opposite direction will be heated up by this hot inert. The heat saving and propagation along the reactor bed is strongly influenced by the switching time, the heat capacity of the inert material, and the reactor design. Improper reactor operation may lead to reactor extinction when the reactor temperature drops progressively, or thermal runaway when the reactor temperature increases monotonically leading to undesired reactions or deactivation of the catalyst. Some applications involve equilibrium-limited reactions or very exothermic reactions, in which cooling or energy extraction-that can be used for heat generation-is necessary to avoid conversion drop or exceeding the critical temperature, which may deactivate the catalyst. The temperature control along the reactor bed becomes a crucial strategy to maintain the reactor under stable heat propagation, which may be performed by cooling the reactor or operating the reactor at a proper switching time. Various modes of RFR cooling have been discussed by Matros and Bunimovich [4]. The reactor parameters such as cooling method or choosing the switching time or reactor design may affect reactor stability. Khinast, et al. [24] studied the conditions that influence the quantitative and qualitative prediction of the so-called cooled RFR dynamics by single- and two-phase models when the catalyst pellet multiplicity does not occur inside the reactor. Rehacek, et al. [11] investigated the chaotic behavior of the RFR in a two-phase model. Khinast, et al. [24] checked the chaotic behavior of the RFR in a single-phase model. Khinast and Luss [25] describe a novel approach for the construction of a bifurcation analysis of the RFR. It was shown that instead of computing the large linearized matrices of the defining conditions first, followed by computing the corresponding eigen values and eigen vectors, it was possible to obtain the product of the linearized matrices and their eigen vectors by Fréchet differentiation of the original model equations. A highly efficient method for computing the periodic states was successfully developed, which enables efficient construction maps of distributed-parameter periodic states. In many RFR designs, the reactor consists of a catalyst section in the reactor center and two layers of inert material at the outer part of the reactor. Some designs insert a space for heat extraction in the center part of the reactor. Contrary to Khinast, et al. [24], who developed a cooled RFR containing a catalyst section only, in this study, the RFR was constructed in five sections, consisting of left inert, left catalyst, heat extraction, right catalyst, and right inert. The objective of this study was to investigate the influence of switching time and heat extraction from the reactor wall on RFR performance for lean methane oxidation. The effects of constant and oscillated feed gas concentrations on reactor stability were also taken into account. Two RFR types were taken into consideration: a cooled RFR with all catalyst 
sections as a base model and an RFR equipped with inert material sections and heat extractor.

\section{Reverse Flow Reactor}

Several methods in dynamic reactor operation have been developed progressively, by researchers such as Prof. Schouten at Eindhoven University of Technology, Prof. Eigenberger at University of Stuttgart, and Dr. Matros at Matros Technologies Inc. Periodic operation has been recognized to offer spectacular benefits when compared to steady state operation. One of the dynamic operations with periodically changing the direction is better known as the reverse flow reactor. It has been widely applied for exothermic and coupling exo-endothermic reactions, both from a viewpoint of energy saving and for manipulation of surface coverage. The combined benefits at a micro-scale (catalyst) and a macro-scale (reactor) can be achieved by using the principle of reverse flow if an appropriate operation procedure is applied. This may produce more favorable gas concentrations and temperature profiles for the catalytic process [16].

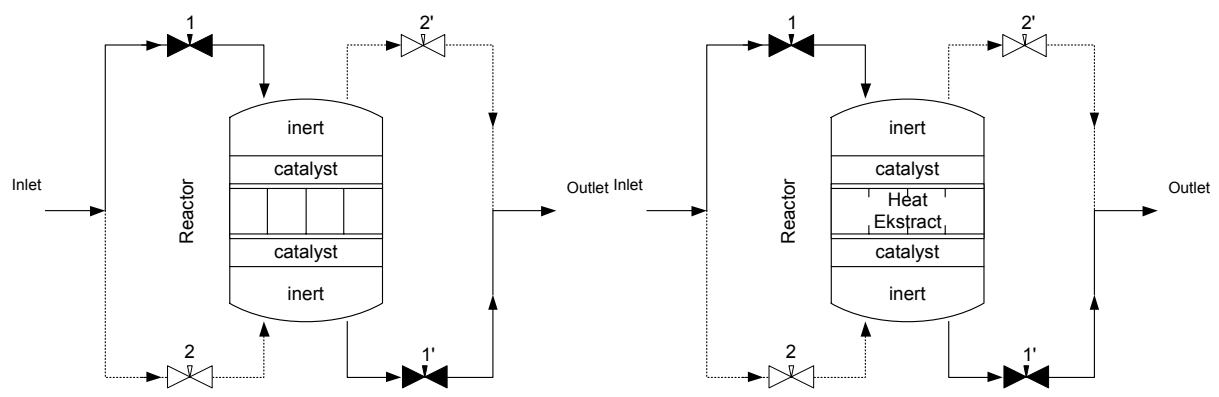

(a)

(b)

Figure 1 Reactor configuration of a reverse flow reactor, consisting of inert, catalyst, and heat extractor. The gas passes through the reactor either forward or backward, depending on flow direction. The change of flow direction can be set at a certain switching time by adjusting the valves, (a) without heat extraction, (b) with heat extraction.

Figure 1 depicts a schematic illustration of a fixed bed for the RFR. In some applications, the RFR consists only of the catalyst section. In this case, the catalyst acts both for chemical reaction acceleration and heat storage. Therefore, the catalyst requirements include a proper active site for reaction and high-heat capacity. Reactor cooling is conducted by taking heat from the reactor wall. During the first half of each cycle, the feed gas enters the reactor in a forward direction, while during the second half of each cycle, the feed gas passes 
through the reactor in a backward direction. Reversing the flow direction periodically at a proper switching time lets us control the heat propagation along the reactor bed, which also influences the local reaction rate and the gas concentration. Many of these applications are catalytic fixed bed reactors with a solid configuration containing outer zones of inert material and an inner zone of catalyst. In particular applications, extending the catalyst bed and reducing or even excluding the inert material are possible when the catalyst acts as reaction accelerator and heat recuperator [4].

\section{Governing Equation}

To model a reactor, a set of mathematical equations is required, expressing the behavior of the reacting system under various operating conditions. The purpose of modeling is to develop thorough and detailed information about a process, which then can be used for predicting the reactor's behavior, for optimizing the design and operation of the process, and eventually for selection among competing novel concepts. The model should allow us to predict the performance for a wide variety of designs and operating conditions. It is necessary to mention at this stage that such a model should include the fundamentals of conservation law, reaction and catalytic engineering, and fixedbed hydrodynamics. After the governing reactor model equations are subjected with supplements of boundary and initial conditions, the model is usually solved simultaneously by using a standard software package.

In this study, lean methane oxidation over Pt based catalyst was used as a model reaction, where the average composition of methane in the feed gas was $1 \%-\mathrm{v}$, while the remainder was air. The stoichiometric reaction of methane combustion can be written as follows:

$$
\mathrm{CH}_{4}+2 \mathrm{O}_{2} \rightarrow \mathrm{CO}_{2}+2 \mathrm{H}_{2} \mathrm{O} \quad \Delta H=-802 \mathrm{~kJ} / \mathrm{mol}
$$

The reaction rate, following the power law, was assumed to be influenced by the methane concentration only as shown in Eq. (2) due to the large excess of air in the feed [3].

$$
r_{C_{4}}=k_{o} \exp \square \frac{E_{a}}{R T} \square\left(C_{C H_{4}}\right)^{0.81}
$$

In the RFR, the domain model of the reactor includes the spatial derivative in time and position, leading to a partial differential model. The model of the RFR becomes more complicated when the reaction rates involved are nonlinear in form. The mathematical models for the RFR are derived from the mass and energy conservation laws. The models are governed by the following equations: 


$$
\begin{gathered}
\left(\varepsilon_{g} c_{g} \rho_{g}+\varepsilon_{s} c_{s} \rho_{s}\right) \frac{\partial T}{\partial t}+u_{s} c_{g} \rho_{g}^{o} \frac{\partial T}{\partial z}-\lambda_{e f f} \frac{\partial^{2} T}{\partial z^{2}}-(-\Delta H) r_{C H_{4}}+a_{w} U\left(T-T_{l}\right)+Q_{E}=0 \\
\frac{\square C_{C H_{4}}}{\square t}=-u_{s} \frac{\square C_{C H_{4}}}{\square z}-r_{C H_{4}}
\end{gathered}
$$

The reaction rates in Eqs. (3) and (4) were applied in the catalyst zone only and $Q_{E}$ was applied in the heat extraction zone only (Model 2).

For forward flow, the boundary conditions of mass and heat balances can be written as:

$$
\begin{aligned}
& C_{C H_{4}}=C_{C H_{4}}^{o} \text { and } \frac{\partial T}{\partial z}=P_{e}\left(T-T_{o}\right) \text { at } z=0 \\
& \frac{\partial T}{\partial z}=0 \text { at } \mathrm{z}=L_{r}
\end{aligned}
$$

For backward flow, the opposite boundary conditions were applied for both mass and heat balances.

$$
\begin{aligned}
& C_{C_{4}}=C_{C_{4}}^{o} \text { and } \frac{\partial T}{\partial z}=P_{e}\left(T-T_{o}\right) \text { at } z=L_{r} \\
& \frac{\partial T}{\partial z}=0 \quad \text { at } z=0
\end{aligned}
$$

\section{$4 \quad$ Results and Discussion}

\subsection{Reverse Flow Reactor without Heat Extraction}

\subsubsection{Inert Configuration}

The initial conditions were the simulated results of the reverse flow operation in which the feed gas and the reactor temperature were set at $773 \mathrm{~K}$ with no heat loss and heat extraction. The reactor configuration consisted of inert-catalystinert. The switching times were varied at $20 \mathrm{~s}, 100 \mathrm{~s}$, and $300 \mathrm{~s}$, and a proper result that shows typical RFR profiles was used for simulation with feed gas temperature at ambient conditions. The kinetic parameters and physical properties used in this study were taken from the literature [26]. Figure 2 presents the simulation results, showing the temperature and concentration profiles along the reactor bed for various switching times. 


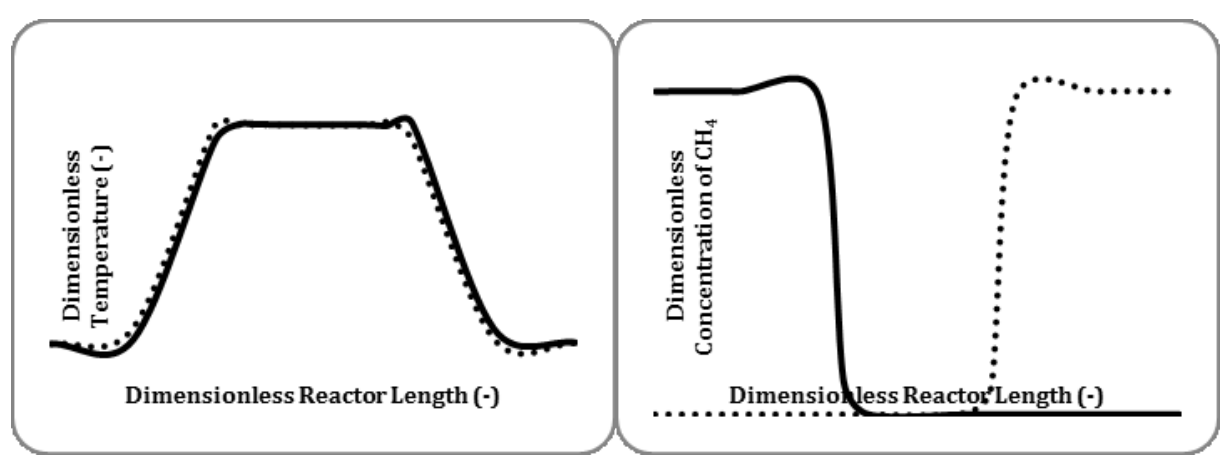

(a) switching time $=20 \mathrm{~s}$

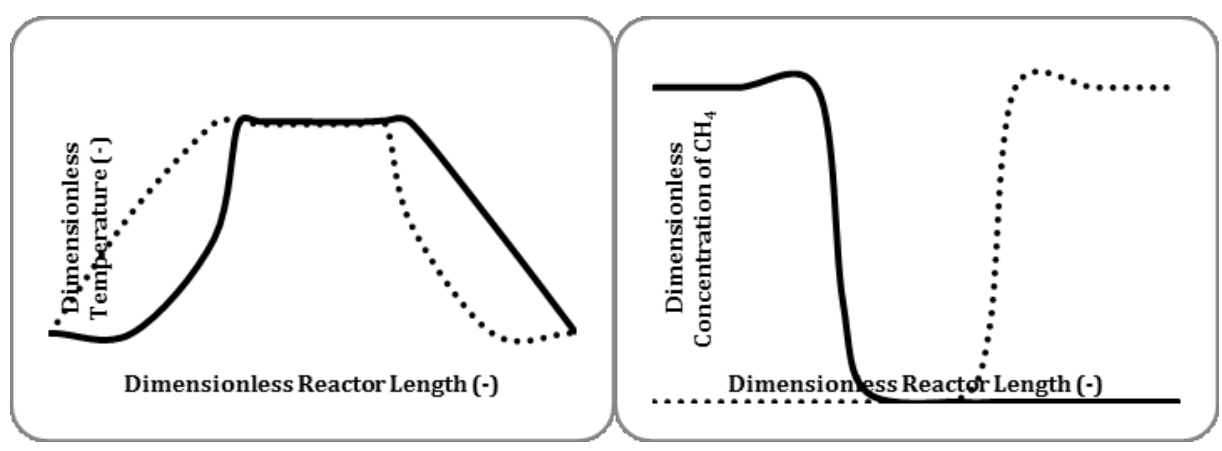

(b) switching time $=100 \mathrm{~s}$

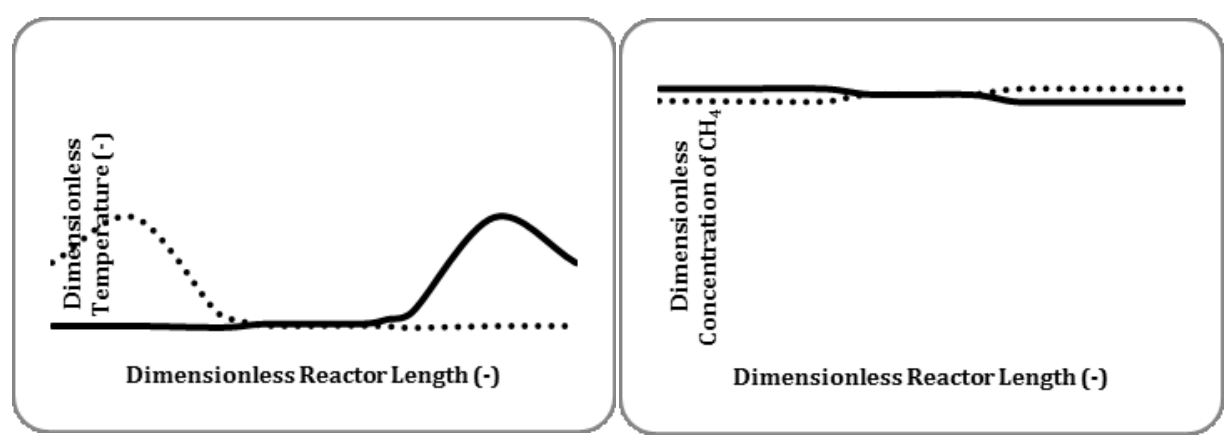

(c) switching time $=300 \mathrm{~s}$

Figure 2 Temperature profiles and methane concentrations along reactor bed at various switching times. No heat loss and heat extraction were employed. These profiles were taken after getting stable oscillation. The dotted line indicates forward flow, while the solid line indicates backward flow.

As can be seen, the influence of the switching time on the dynamic behavior of heat propagation and methane concentration along the reactor bed are indicated. The temperature and methane concentration profiles along the reactor bed were 
taken at the beginning of every cycle, immediately after reversing the flow direction. These profiles (solid line for right direction and dotted line for left direction) constitute the mirror effect. In between, there are intermediate heat and mass propagations that may influence process performance. In the case of a switching time of $20 \mathrm{~s}$, both profiles (forward and backward) nearly coincided, while at a switching time of $100 \mathrm{~s}$, the forward and backward flows were not close, which means that the heat propagation occurs over a longer distance. A higher temperature peak was obtained when the change of flow direction was more frequent. Therefore, at switching times of $20 \mathrm{~s}$ and $100 \mathrm{~s}$, the accumulation of heat due to the exothermic reaction induced the heat trap effectively, as indicated by the higher temperature profile in the reactor centre. These time scales exhibit proper conditions for typical flow reversal, also shown by the complete conversion of methane. In the configuration without heat extraction, at a sort switching time $(20 \mathrm{~s})$, the temperature profile developed along the reactor bed nearly coincided between forward and reverse flow, which means that no significant heat propagation occurred in the reactor bed. A temperature profile was developed but the value at every axial position stayed almost constant.

On the other hand, when the switching time was $300 \mathrm{~s}$ or higher, the heat trap could not be created in the reactor centre. The heat flowed out from the reactor system, as shown in Figure 2(c), leading to reactor extinction with very low methane conversion. Based on this observation, determination of the proper switching time is indispensable for operating the reverse flow reactor.

The switching time also influenced the heat accumulation inside the reactor and $\mathrm{CH}_{4}$ loss due to slip and unconverted $\mathrm{CH}_{4}$, as presented in Figure 3. The heat accumulation decreased with an increase in switching time, while the methane loss decreased until about $180 \mathrm{~s}$, and subsequently increased. The amount of heat that can be trapped by the packed bed will decrease when the heat convection by the stream becomes dominant. Therefore, at a longer switching time, the heat contained in the stream will flow out of the reactor. The higher methane loss at a longer switching time is induced by the lower reaction temperature in the reactor centre, leading to a lower degree of conversion. On the other hand, the higher methane loss at a shorter switching time is caused by methane slip due to the fast flow direction change. The configuration of the fixed bed reactor consists of $33 \%$ inert, each at the outer part of the reactor. This region will contribute to methane slip at every switch of flow direction. 


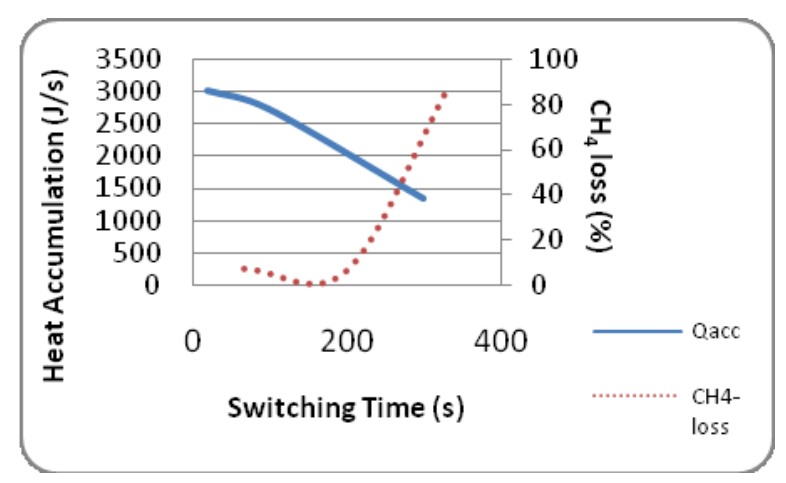

Figure 3 The influence of switching time on heat accumulation and methane loss.

\subsubsection{Cooled Reverse Flow Reactor}

In many cases, the RFR predominantly converges to a symmetric state, for both the spatial temperature profile and the concentration profile at two consecutive flow reversals are mirror images of each other. If the reactor is cooled in some way, or the operation is not adiabatic, as is often encountered in experimental observations, several intricate dynamical features are obtained [24,25]. Firstly, moderate cooling leads to temperature profiles with two maxima, while only one flat maximum exists under adiabatic conditions. Profiles with two maxima are often observed in experimental studies [27], a clear indication of insufficient reactor insulation. If the reactor cooling is increased, the symmetric profiles become unstable and either a periodic asymmetric, a quasi-periodic or a chaotic state is obtained. In this study, the influence of switching time on the symmetricity of the reactor operation with flow reversal was investigated. The simulation results are presented in Figure 4.

At a very short switching time $(10 \mathrm{~s})$, the temperature profile as a function of reactor length did not form a symmetric distribution between the right and left direction. Depending on the initial temperature profile, the heat propagation along the reactor bed in between two switching times is indicated in Figure 4(a). When the heat travels along the reactor bed, the temperature profile is reversed before it reaches steady state condition. Therefore, a symetric temperature profile cannot be achieved when the switching time is too short. A symmetric temperature profile may result from a non-uniform process performance between forward flow and backward flow. When the switching time was increased to $20 \mathrm{~s}$, the temperature profiles at the end of the cycle between forward and backward flow showed the mirror effect and were symmetric (see Figure 4(b)). This means that the reactor system may respond to the flow direction change with the same capability for storing heat in solid material and 
releasing the heat to cold feed gas. Figure 4(c) confirms that longer switching times made the reverse flow reactor become symmetric in operation and ensured that reactor performance was similar for both flow gas directions.

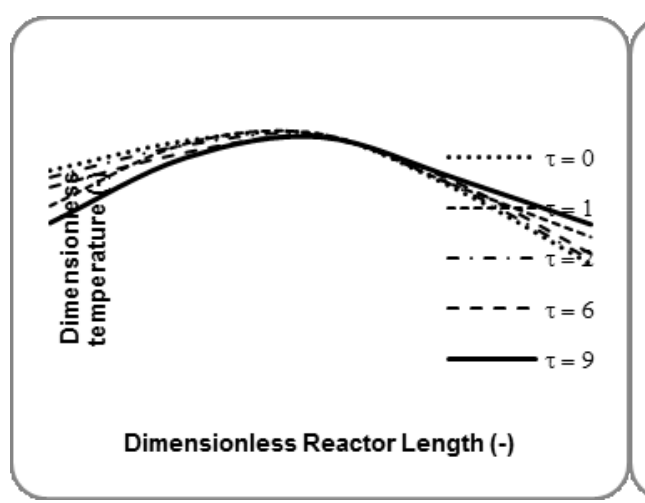

(a) Switching time $=10 \mathrm{~s}$

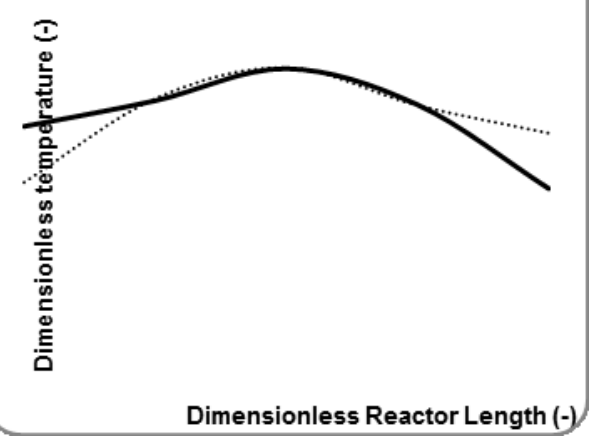

(b) Switching time $=20 \mathrm{~s}$

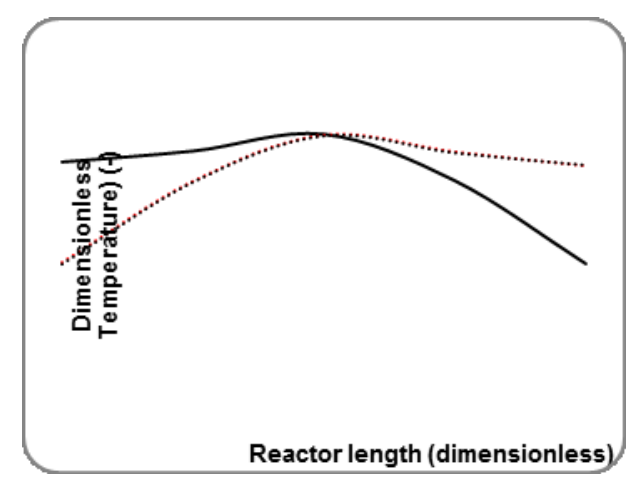

(c) Switching time $=30 \mathrm{~s}$

Figure 4 Dimensionless reactor temperature as a function of dimensionless reactor length at various cycle times (dotted line for $\tau=1,3,5, \ldots$ (right direction), solid line for $\tau=0,2,4, \ldots$ (left direction)).

\subsection{Comparison of RFR with and without Heat Extraction}

A transient operation according to the reverse flow principle with nonlinear kinetic parameter gives rise to complicated dynamic behavior of the fixed bed reactor for the classical application of energy saving, as has been reported on several occasions $[25,28]$. This complexity is due to the nonlinear dynamics of the whole system, induced by nonlinear reaction kinetics on the scale of a catalytic active site, in combination with heat transfer aspects on the scale of the reactor. 
The gas emission of methane vented by a coal mine or a leak from a piping system of natural gas usually occurs at ambient temperature. This low temperature requires a large amount of heat to achieve the reaction temperature (around $500^{\circ} \mathrm{C}$ ). In addition, the low concentration of methane emission only provides an adiabatic temperature rise of $100-200^{\circ} \mathrm{C}$, indicating that a pre-heater is necessary when a conventional fixed bed reactor in once-through operation is used. In this study, the natural phenomena of heat loss through the reactor wall and heat extraction were employed. The heat loss occurs from the whole reactor wall (which is represented in the heat loss number), while the heat extraction (HE) was performed for the HE section only. Heat extraction was maintained constant at $17 \mathrm{~W}$ per $9.3 \mathrm{~g}$ feed gas/h based on a preliminary simulation.

A typical temperature profile along the reactor bed in the case of involving heat accumulation and heat extraction looks similar to that of an RFR without heat accumulation and heat extraction (see Figure 5). A lower decrease of temperature, however, took place in the middle part of the reactor (HE section) due to heat extraction. At a short switching time, $20 \mathrm{~s}$, the temperature profiles for forward and backward flow almost coincided. In this condition, the heat accumulation in the reactor decreased at $-0.04 \mathrm{~W}$, which gave rise to a lower temperature in the reactor centre when compared to a switching time of $100 \mathrm{~s}$. The latter indicated better performance: the heat accumulated at a rate of +0.02 $\mathrm{W}$, leading to a higher reactor temperature at the centre. As a result, the methane loss at a switching time of $20 \mathrm{~s}$ was slightly higher compared to a switching time of $100 \mathrm{~s}$.

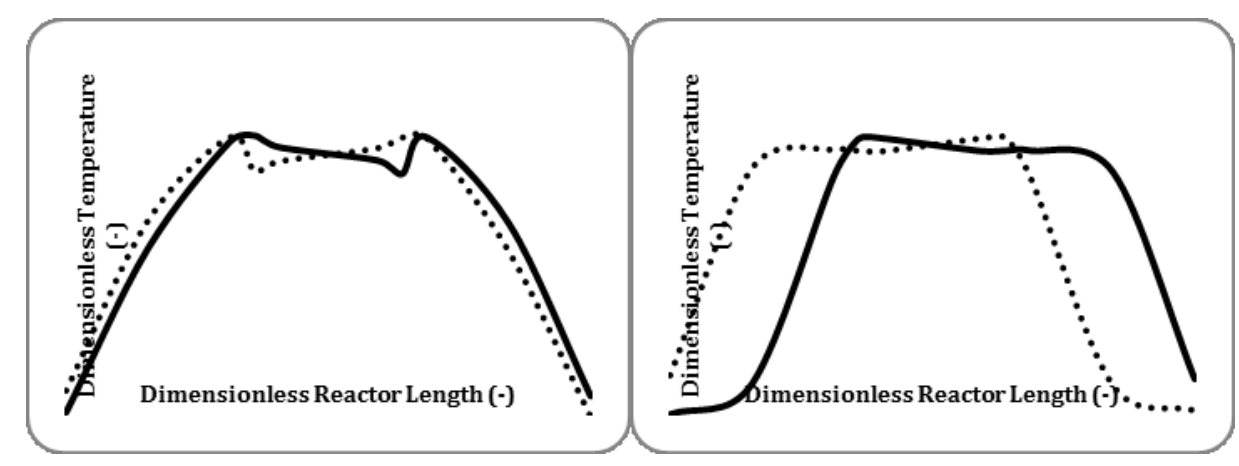

Figure 5 Temperature profile along reactor bed at various switching times: (a) switching time $=20 \mathrm{~s}, Q_{a c c}=-0.04 \mathrm{~W}$, which means tending to extinction, $\mathrm{CH}_{4, \text { loss }}=0.6 \%$; (b) switching time $100 \mathrm{~s}, Q_{a c c}=0.02 \mathrm{~W}, \mathrm{CH}_{4, \text { loss }}=0.13 \%$. The dotted line indicates backward flow, while the solid line indicates forward flow. Feed gas temperature was $303 \mathrm{~K}$. The inert materials are at the outer part of the catalyst bed. 


\subsection{Stability Analysis of Reverse Flow Reactor}

In practice, adiabatic reactor operation can hardly be achieved, even if thick isolation is equipped over the reactor wall. Contrary to Khinas, et al. [24], who used cooling capacity as key parameter in determining the performance of an RFR, in this study the heat loss number was applied and incorporated in the heat balance. In addition, heat extraction was the parameter to be investigated. According to the above discussion, at a switching time longer than $20 \mathrm{~s}$, the symmetricity of the reverse flow reactor is developed. This was also observed in this case, with heat loss and heat extraction involved. Obviously, the heat loss number did not affect the symmetricity of the RFR at a switching time of $100 \mathrm{~s}$. The RFR was still able to operate under stable oscillation at various heat loss numbers, spanning from 0 to 500, as shown in Figure 5. At adiabatic operation, the inert material downstream of the catalyst may achieve a similar temperature to the catalyst section. This means that all heat released by the exothermic reaction is stored in the reactor and will be utilized for heating up the cold feed gas during the subsequent cycle. However, an adiabatic reactor is not a real one and this can hardly be achieved during real operation. When the cooling capacity increased, the temperature profiles along the reactor bed, both for forward flow and backward flow, still indicated symmetricity. This means that at a switching time of $100 \mathrm{~s}$, the heat loss number did not influence reactor stability and did not give rise to chaos. A comparison of the temperature profiles along the reactor bed is presented in Figure 6. The heat extraction strongly induced the temperature profile. At $Q_{E}=0$, the temperature profile in the centre part of the reactor looks flat and it decreased in the downstream region. In this region, the lower temperature was induced by the low temperature of the feed gas during the previous cycle. After the flow direction was changed, a similar temperature profile can be observed where the temperature profile shifted up, but was still lower than the temperature in the reactor centre. When heat extraction $Q_{E}$ increased up to $17 \mathrm{~W}$, the temperature profile was slightly different to that of the reverse flow reactor without heat extraction. In this case, the temperature profile in the reactor centre formed a slight upward concave curve due to the heat extraction. The influence of heat extraction on the temperature profile is seen at higher values for $Q_{E}$, for instance at $Q_{E}=34 \mathrm{~W}$ and even at $Q_{E}=68 \mathrm{~W}$. Other observations are that the maximum temperature decreased. At $Q_{E}=68 \mathrm{~W}$, too much heat is withdrawn from the reactor, leading to a lower temperature inside the reactor bed and at the outer part of the catalyst section, the temperature dropping markedly. This condition may endanger the reactor, leading to extinction. Therefore, heat extraction should be accomplished under proper operating conditions with the aim to generate energy taken from the exothermic reaction and to avoid catalyst damage due to overheating the reactor centre. 

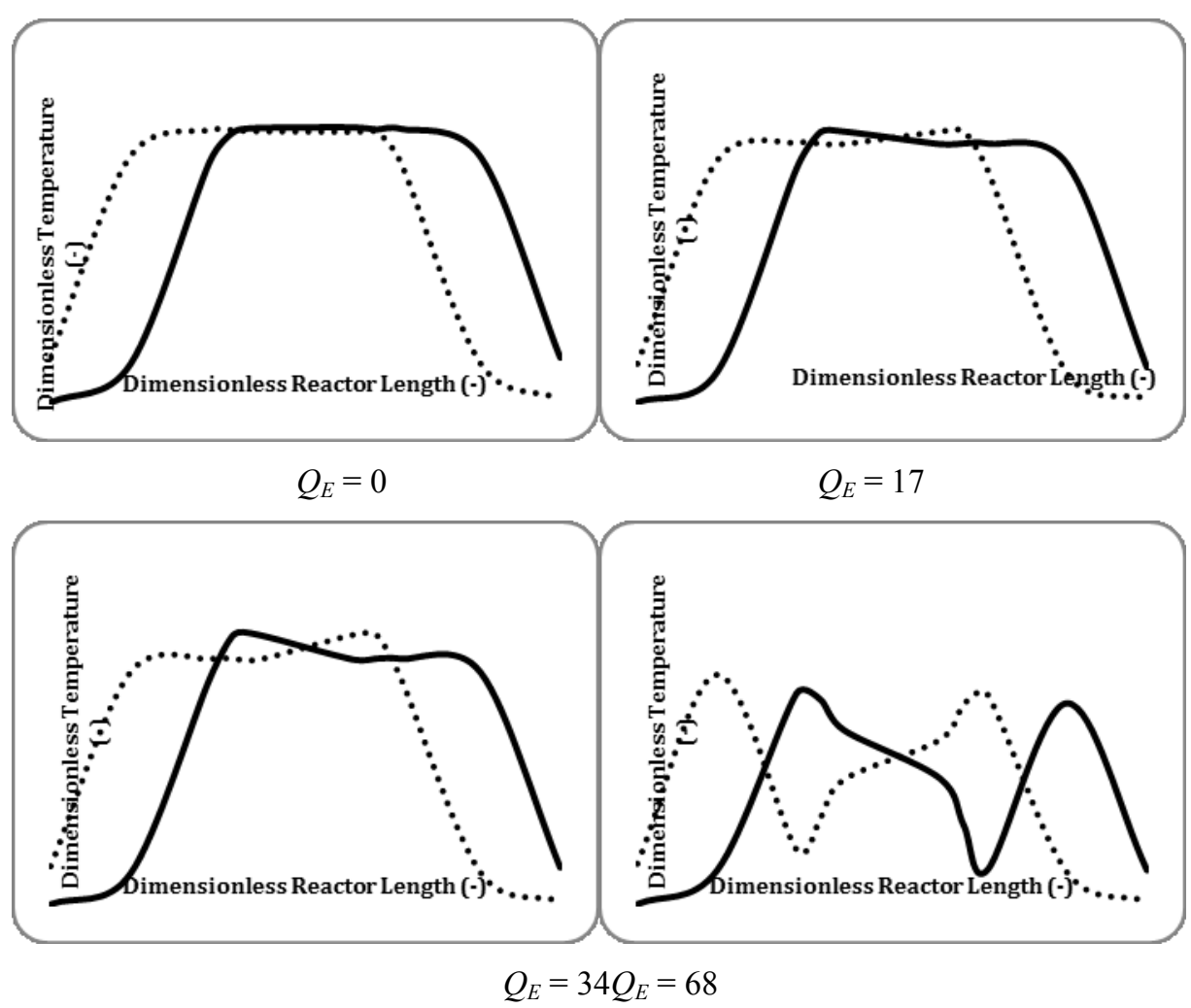

Figure 6 Dimensionless temperature profile along dimensionless reactor length at various heat extractions $\left(Q_{E}\right)$ for Model Reactor I (only catalyst section). The heat loss through the reactor wall was incorporated in the energy balance. Feed temperature was $303 \mathrm{~K}$ and switching time $100 \mathrm{~s}$.

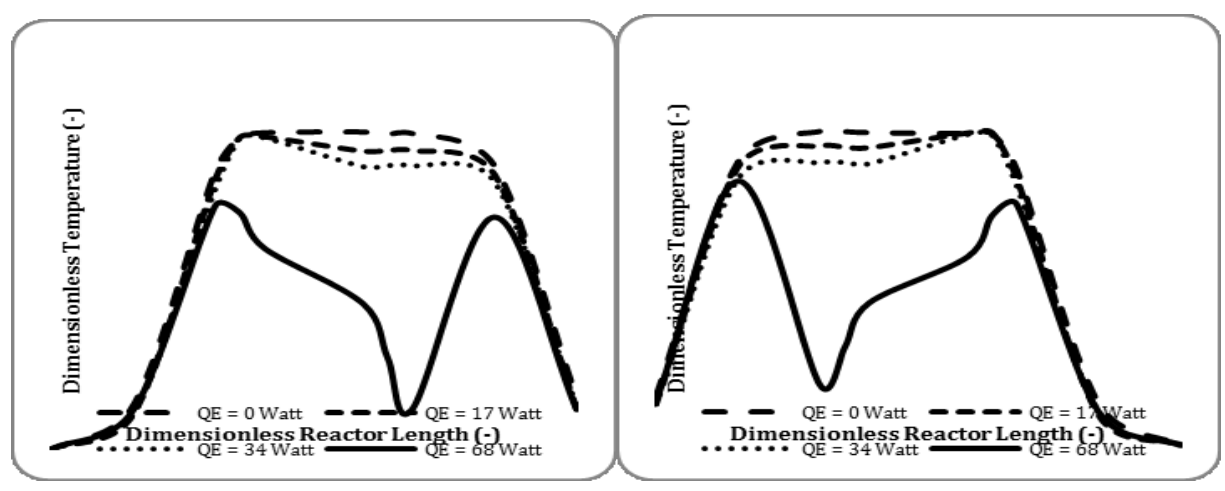

Figure 7 Dimensionless temperature profile as a function of dimensionless reactor length at various heat loss numbers. Adiabatic condition is indicated by $Q_{E}=0$. Switching time was $100 \mathrm{~s}$. Flow direction is forward (left) and backward (right). 
Figure 7 shows the symmetricity of the reverse flow reactor at various heat extraction values. The symmetricity of the reverse flow reactor held for a heat extraction range of $0-68 \mathrm{~W}$. This obviously shows that the heat extraction affected the heat accumulation in the reverse flow reactor as indicated by the temperature profile along the reactor. At a large heat extraction, the heat accumulation inside the reactor became low, leading to extinction. However, the reverse flow reactor still showed symmetricity.

The stability of the reverse flow reactor is another crucial factor to be considered. It too, can be observed by varying the switching time and considering its influence on reactor stability. In this case, the reactor stability is expressed in the heat accumulation as a function of cycle number. The heat accumulation basically indicates the amount of heat that can be stored inside the reactor bed. If the amount of heat stored increases due to the reaction heat released by the exothermic reaction, the heat accumulation may increase, but it will depend on the switching time. Therefore, investigation of this matter becomes necessary, since switching time is a key factor in reverse flow reactors [29]. Figure 8 shows the dynamic behavior of the reverse flow reactor at switching times of $50 \mathrm{~s}, 100 \mathrm{~s}$, and $150 \mathrm{~s}$ as a function of cycle number. In Figure 8(a), the heat accumulation increased at the beginning of operation up to its maximum value, subsequently decreasing markedly, even lower than its value at the beginning. In this case, setting a switching time of $150 \mathrm{~s}$ induced the heat flowing out of the reactor with the outlet stream. This means that the rates of heat conduction and convection were faster than the rate of heat storing. This condition results in heat propagation along the reactor bed for too long a distance, leading to heat loss through the product stream. Therefore, it is necessary to decrease the switching time in order to maintain proper heat propagation inside the reactor bed. It was set at $50 \mathrm{~s}$ for the second trial, which resulted in too fast a switching time. As can be seen in Figure 8(b), the heat accumulation inside the reactor bed increased as a function of cycle number. The aim of reversing the flow direction seems to be achieved, but when the heat accumulation inside the reactor continuously increases, the reactor temperature will also increase, which may lead to reactor runaway or overheating. If this switching time is chosen, some heat must be withdrawn from the reactor in order to avoid reactor and catalyst damage due to overheating. At an intermediate switching time value, it was observed that the dynamic behavior of the reverse flow reactor produced stability during operation when the switching time was $100 \mathrm{~s}$. When no heat extraction is installed, this switching time is suitable for operating the reactor. 


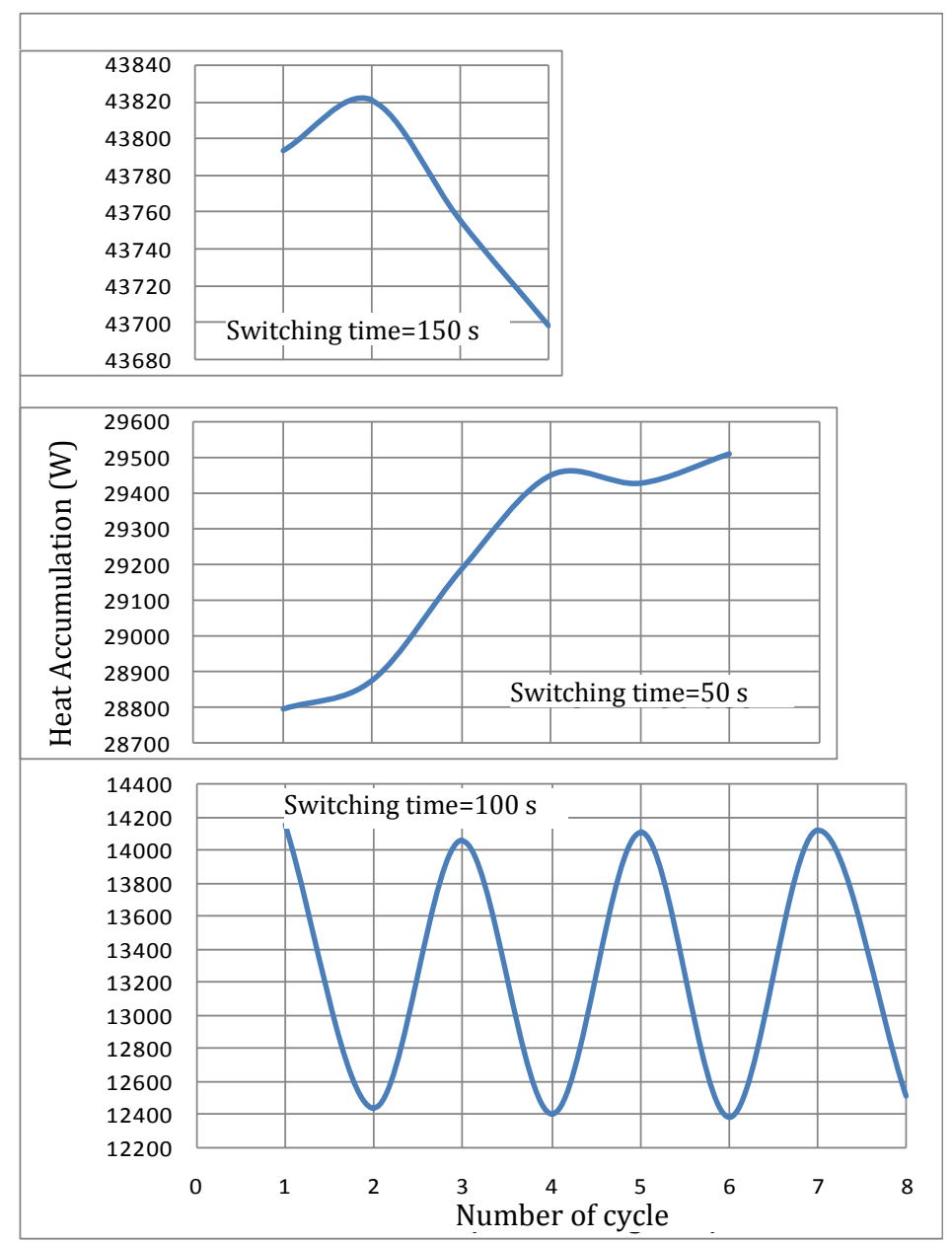

Figure 8 Heat accumulation inside the reverse flow reactor as a function of number of cycle at switching times of 50,100 , and $150 \mathrm{~s}$.

\section{Conclusion}

The study of RFR stability for lean methane oxidation with constant and oscillating feed concentration has been performed. The switching time showed a strong influence on reactor stability, design and operation, both with and without heat extraction. In the configuration without heat extraction, at a short switching time, the temperature profile developed along the reactor bed nearly coincided between forward and reverse flow, which means that no significant heat propagation occurred in the reactor bed. A temperature profile was developed, but the value at every axial position stayed almost constant. At a 
higher switching time, heat propagation along the reactor bed could be observed clearly. However, a switching time that is too long induces heat loss through the effluent. When heat extraction was applied, the reverse flow reactor could still maintain its stability during operation, but when the heat extraction was too great, the stability of the reactor decreased. The heat accumulation inside the reactor was affected by the switching time. Too short or too long switching times resulted in instability of the reactor.

\section{Acknowledgements}

The financial support partially provided by International Research of ITB 2010 is gratefully acknowledged. Special credit goes to PDE Solutions for their technical support in the development of the model script.

\section{Notations}

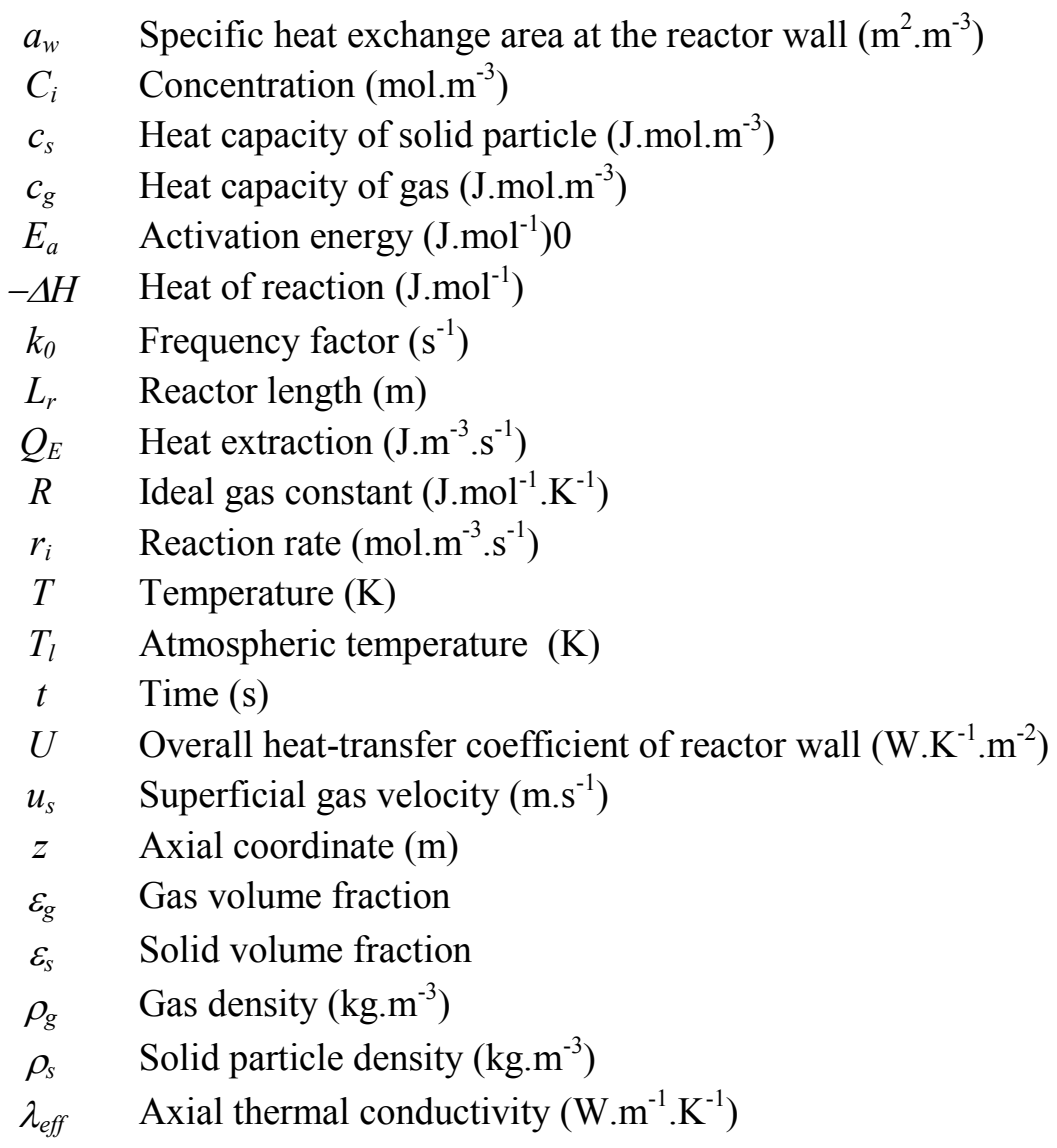




\section{References}

[1] Hayes, R.E., Catalytic Solutions for Fugitive Methane Emissions in the Oil and Gas Sector, Chemical Engineering Science, 59, pp. 4073-4080, 2004.

[2] Becker, E., Carlsson, P.A., Kylhammar, L., Newton, M.A. \& Skoglundh, M., In Situ Spectroscopic Investigation of Low-Temperature Oxidation of Methane over Alumina-Supported Platinum during Periodic Operation, The Journal of Physical Chemistry C, 115, pp. 841-1374, 2010.

[3] Gosiewski, K. \& Warmuzinski, K., Effect of the Mode of Heat Withdrawal on the Asymmetry of Temperature Profiles in Reverse-Flow Reactors. Catalytic Combustion of Methane as a Test Case, Chemical Engineering Science, 62, pp. 2679-2689, 2007.

[4] Matros, Yu.Sh. \& Bunimovich, G.A., Reverse-Flow Operation in Fixed Bed Catalytic Reactors, Catalysis Reviews-Science and Engineering, 38(1), pp. 1-68, 1996.

[5] Cottrell, F.G., Purifying Gases and Apparatus Therefor, U.S. Patent Office, 2, pp. 121, 733, 1938.

[6] Boreskov, G.K., Matros, Yu.Sh. \& Kiselev, O.V., Catalytic Processes under Nonsteady-State Conditions I, Thermal Front in the Immobile Catalyst Layer, Kinetics and Catalyst, 20(3), pp. 773-780, 1979.

[7] Boreskov, G.K. \& Matros, Yu.Sh., Flow Reversal of Reaction Mixture in a Fixed Catalyst Bed-a Way to Increase the Efficiency of Chemical Processes, Applied Catalysis, 5(3), pp. 337-343, 1983.

[8] Eigenberger, G. \& Nieken, U., Catalytic Combustion with Periodic Flow Reversal, Chemical Engineering Science, 43(8), pp. 2109-2115, 1988.

[9] Thullie, J. \& Burghardt, A., Application of the Flow Reversal Reactor to the Methanol Synthesis, Un-steady State Processes in Catalysis, UtrechtTokyo: VNU Science Press, pp. 687-692, 1990.

[10] Van de Beld, B., \& Westerterp, K.R., Air Purification by Catalytic Oxidation in a Reactor with Periodic Flow Reversal, Chemical Engineering and Technology, 17, pp. 217-226, 1994.

[11] Rehacek, J., Kubicek, M. \& Marek, M., Periodic, Quasi Periodic and Chaotic Spatiotemporal Patterns in a Tubular Catalytic Reactor with Periodic Flow Reversal, Computers and Chemical Engineering, 22(1-2), pp. 283-297, 1998.

[12] Matros, Yu.Sh., Catalytic Processes under Unsteady State Conditions, Elsevier, Amsterdam, 1989.

[13] Froment, G.F. \& Bischoff, K.B., Chemical Reactor Engineering Analysis and Design, $2^{\text {nd }}$ edition, John Wiley \& Sons, New York, 1990.

[14] Vanden Bussche, K.M., Neophytides, S.N., Zolotarskii, I.A. \& Froment, G.F., Modelling and Simulation of the Reversed Flow Operation of a 
Fixed-Bed Reactor for Methanol Synthesis, Chemical Engineering Science, 48(19), pp. 3335-3345, 1993.

[15] Sapundzhiev, C., Bunimovich, G.A., Drobishvich, V.I., Grozev, G., Yausheva, L.V., Matros, Yu.Sh. \& Elenkov, D., Effect of Heat Loss on Operation of Reactors with Periodic Reverse Gas Feed, Theoretical Fundamentals in Chemical Engineering, 22(3), pp. 349-355, 1988.

[16] Ferreira, R.Q., Costa, C.A. \& Masetti, S., Reverse Flow Reactor for a Selective Oxidation Process, Chemical Engineering Science, 54(20), pp. 4615-4627, 1999.

[17] Bobrova, L.N., Slavinskaya, E.M., Noskov, A.S. \& Matros, Yu.Sh., Unsteady-State Performance of Nitrogen Oxide (NOx) Catalytic Reduction by Ammonia, Reaction Kinetics and Catalysis Letters, 37(2), pp. 267-272, 1988.

[18] Jirát, J., Kubíček, M. \& Marek, M., Mathematical Modelling of Catalytic Monolithic Reactors with Storage of Reaction Components on the Catalyst Surface, Catalysis Today, 53(4), pp. 583-596, 1999.

[19] Matros, Yu.Sh., Bunimovich, G.A., Strots, V.O. \& Mirosh, E.A., Reversed Flow Converter for Emission Control After Automotive Engines, Chemical Engineering Science, 54(13-14), pp. 2889-2898, 1999.

[20] Neophytides, S.G., Marchi, A.J. \& Froment, G.F., Methanol Synthesis by Means of Diffuse Reflectance Infrared Fourier Transform and Temperature-Programmed Reaction Spectroscopy, Applied Catalysis A: General, 86(1), pp. 45-64, 92.

[21] Budhi, Y.W., Jaree, A., Hoebink, J.H.B.J. \& Schouten, J.C., Simulation of Reverse Flow Operation for Manipulation of Catalyst Surface Coverage in the Selective Oxidation of Ammonia, Chemical Engineering Science, 59, 2004.

[22] Budhi, Y.W., Hoebink, J.H.B.J. \& Schouten, J.C., Reverse Flow Operation with Reactor Side Feeding: Analysis, Modeling, and Simulation, Industrial and Engineering Chemistry Research, 43, 2004.

[23] Barresi, A.A., Baldi, G. \& Fissore, D., Forced Unsteady-State Reactors as Efficient Devices for Integrated Processes: Case Histories and New Perspectives, Industrial and Engineering Chemistry Research, 46, pp. 8693-8700, 2007.

[24] Khinast, J., Gurumoorthy, A. \& Luss, D., Complex Dynamic Features of a Cooled Reverse-Flow Reactor, AIChE Journal, 44(5), pp. 1128-1140, 1998.

[25] Khinast, J.G. \& Luss, Efficient Bifurcation Analysis of PeriodicallyForced Distributed Parameter Systems, Computer and Chemical Engineering, 24, pp. 139-152, 2000.

[26] Kushwaha, A., Poiriera, H.M., Sapoundjiev, H. \& Hayes, R.E., Effect of Reactor Internal Properties on the Performance of a Flow Reversal 
Catalytic Reactor for Methane Combustion, Chemical Engineering Science, 59, pp. 4081-4093, 2004.

[27] Nieken, U., Gregorios, K. \& Eigenberger, G., Limiting Cases and Approximate Solutions for Fixed-Bed Reactors with Periodic Flow Reversal, AIChE Journal, 41(8), pp. 1915-1925, 1995.

[28] Salinger, A.G. \& Eigenberger, G., The Direct Calculation of Periodic States of the Reverse Flow Reactor-I, Methodology and Propane Combustion Results, Chemical Engineering Science, 51(21), pp. 49034913, 1996.

[29] Barresi, A.A. \& Vanni, M., Control of Catalytic Combustors with Periodical Flow Reversal, AIChE J, 48, pp. 648-652, 2002. 